\title{
Land Prices and Unemployment ${ }^{\text {th }}$
}

\author{
Zheng Liu ${ }^{\mathrm{a}}$, Jianjun Miao ${ }^{\mathrm{b}}$, Tao Zha ${ }^{\mathrm{c}, *}$ \\ ${ }^{a}$ Federal Reserve Bank of San Francisco, 101 Market Street, San Francisco, CA 94105. \\ Email: zliu001@gmail.com \\ ${ }^{b}$ Department of Economics, Boston University, 270 Bay State Road, Boston, MA 02215, \\ USA, CEMA, Central University of Finance and Economics, and AFR, Zhejiang \\ University, China. Email: miaoj@bu.edu \\ ${ }^{c}$ Federal Reserve Bank of Atlanta, 1000 Peachtree Street, N.E., Atlanta, GA 30309-4470; \\ Emory University, Department of Economics, 1602 Fishburne Drive, Atlanta, GA \\ 30322-2240; and NBER.Email: zmail@tzha.net
}

\begin{abstract}
We integrate the housing market and the labor market in a dynamic general equilibrium model with credit and search frictions. We argue that the labor channel, combined with the standard credit channel, provides a strong transmission mechanism that can deliver a potential solution to the Shimer (2005) puzzle. The model is confronted with U.S. macroeconomic time series. The estimation results account for two prominent facts observed in the data. First, land prices and unemployment move in opposite directions over the business cycle. Second, a shock that moves land prices also generates the observed large volatility of unemployment.
\end{abstract}

Keywords: Housing and labor markets, labor channel, real wage rigidity, intensive and extensive margins, unemployment

\footnotetext{
J JEL Classification: E21, E27, E32, E44. Critical comments from Larry Christiano, the anonymous referee, and the editor have led to a significant improvement of this paper. We thank Marty Eichenbaum, Pat Higgins, Matteo Iacoviello, Nir Jaimovich, Alejandro Justiniano, Monika Piazzesi, Pietro Peretto, Sergio Rebelo, Richard Rogerson, Martin Schneider, Bob Shimer, Lars Svensson, and seminar participants at Duke University, the European Central Bank, the Federal Reserve Banks of Atlanta, Chicago, and San Francisco, Goethe University, NBER Summer Institute, Northwestern-Tsinghua Macro Conference, the Sveriges Riksbank, University of Chicago, and University of Georgia for helpful discussions. This research is supported in part by the National Science Foundation Grant SES 1127665. The views expressed herein are those of the authors and do not necessarily reflect the views of the Federal Reserve Banks of Atlanta and San Francisco or the Federal Reserve System or the National Bureau of Economic Research.

${ }^{*}$ Corresponding author. Tel: +1 404-498-8353.

Email address: zmail@tzha.net (Tao Zha)
} 


\section{Introduction}

A striking feature of business cycles is that land prices and unemployment comove (Figure 1). Never is this feature more true than in the Great Recession, when the collapse in the housing market was followed by a sharp rise of unemployment. We use a Bayesian vector autoregressions (BVAR) model to quantify the comovements between land prices and unemployment, along with other key macroeconomic variables. As shown in the left column of Figure 2 (solid lines and shaded areas), a negative shock to the land price leads to a simultaneous rise in unemployment and a decline in the land price and total hours, whereas the real wage responses are relatively weak 1 A structural analysis of these stylized facts is essential for policy analysis as well as for understanding business cycles in general.

The goal of this paper is to deliver a structural analysis of dynamic links between land prices and unemployment and to establish the empirical relevance of this analysis. We focus on land prices because fluctuations of house prices are mostly driven by those of land prices (Davis and Heathcote, 2007; Nichols et al. 2013). To establish the link between the land price and the unemployment rate, we combine the housing market and the labor market in one unified dynamic stochastic general equilibrium (DSGE) framework. To fit U.S. macroeconomic time series, we introduce both financial and search-matching frictions in the model.

The model consists of three types of agents: households, capitalists, and firms. The representative household consists of a continuum of workers - some are employed and others are not. All workers consume the same amount of goods and housing services, so that unemployment risks are pooled within the household. The representative capitalist owns all firms, each of which employs one worker and operates a constant-returns-to-scale technology that transforms labor, land, and capital into final consumption goods.

The representative capitalist's consumption, investment, and land acquisition require external financing. Since contract enforcement is imperfect, the borrowing capacity of the capitalist is limited by the values of collateral assets, which include the capitalist's holdings of capital and land (Kiyotaki and Moore, 1997; Iacoviello, 2005; Liu et al., 2013). We model the labor market within the framework of Diamond (1982), Mortensen (1982), and Pissarides (1985) (DMP hereafter).

Econometric estimation of our structural model shows that a negative housing demand shock generates small and sluggish responses of real wages but large

1 A complete set of impulse responses to a land price shock in the BVAR with seven variables is presented in Figure 1 of Supplemental Appendix A. The seven variables are consumption, investment, job vacancies, unemployment, total hours, real wages, and land prices. As a comparison, the same figure displays the estimated impulse responses of these variables following a negative housing demand shock in our DSGE model. In Supplemental Appendix A, we provide a full description of the BVAR, our treatment of possible cointegration, and our recursive identification assumptions (see also Section 5 . 
and persistent comovements among the land price, the unemployment rate, consumption, investment, job vacancies, and total hours, consistent with the styled facts produced by the BVAR in Figure 2. Moreover, a shock that moves the land price is capable of generating large volatility of unemployment, as we observe in the data. These empirical results suggest that our model contains an economically substantive transmission mechanism.

Davis and Heathcote (2007) emphasize the importance of housing demand in their land-price regression exercises. We make their concept of housing demand more concrete by specifying a housing demand shock as a preference shock in the household's utility function of housing services. Such a preference shock, like other shocks in all DSGE models, is a reduced-form representation of an exogenous disturbance at a micro level. Liu et al. (2009) present one interpretation by studying an economy with heterogeneous households that experience idiosyncratic and uninsurable liquidity shocks and face collateral constraints. In the aggregated version of that model, there is a term in the housing Euler equation that corresponds to a preference shock in our model's household utility function. As a result, financial innovations or deregulations that relax households' collateral constraints and expand their borrowing capacity in the disaggregated model would translate into a positive housing demand shock at the aggregate level.

The transmission from housing demand shocks to fluctuations in the land price and the unemployment rate works through both the credit channel and the labor channel. The credit channel is similar to the standard financial multiplier; it embodies the dynamic interactions between the collateral value and the value of a new employment match. A decline in housing demand lowers the equilibrium land price and thus the collateral value of land. As the borrowing capacity for the capitalist shrinks, investment spending falls. The decline in investment lowers future capital stocks. Since capital and labor are complementary factors of production, a decrease in future capital stocks lowers future marginal productivity of each employed worker and thus reduces the present value of a new employment match. The firm responds by posting fewer job vacancies, leading to a fall in the job finding rate and a rise in the unemployment rate ${ }^{2}$

The labor channel is a new discovery of this paper; it produces endogenous wage rigidities in response to a decline in housing demand as shown in Figure 2. A negative housing demand shock leads to a fall of the land price and, through the credit channel, an increase of unemployment. This creates a negative wealth effect that reduces household consumption. The reduction of consumption, however, is offset by a substitution effect because a negative housing preference shock encourages the household to substitute (non-housing) consumption for housing services. Since the decline of consumption is mitigated, the rise in the marginal utility of consumption is also dampened. Consequently, workers' reservation wages fail to fall, producing endogenous wage rigidities fol-

${ }^{2}$ Our estimation shows that fluctuations in collateral value are primarily driven by changes in the value of land, but not much by changes in the value of capital. 
lowing a housing demand shock. This labor channel- the endogenous wage rigidity in particular - is consistent with the BVAR evidence; it plays a crucial role for generating a large response of unemployment and its persistent comovement with the land price.

An important challenge for business cycle models built on the DMP theoretical framework is to generate a large volatility in the labor market (Shimer, 2005). To meet this challenge, Hagedorn and Manovskii (2008) and Hornstein et al. (2005) argue that the volatility of unemployment (relative to that of labor productivity) in DMP models can be obtained by making the replacement ratio parameter extremely high. By replacing the standard Nash bargaining problem with an alternating-offer bargaining protocol in the spirit of Hall and Milgrom (2008), Christiano et al. (2013) show that their model with a lower value of the replacement ratio can account for a high volatility in the labor market according to the statistic considered by Shimer (2005) - the ratio of the standard deviation of labor market tightness (the job vacancy rate divided by the unemployment rate) to the standard deviation of aggregate labor productivity. We call this ratio "the Shimer volatility ratio."

The original analysis of Shimer 2005) emphasizes the effects of a stationary technology shock. Our analysis focuses on a housing demand shock because this is the shock that can move the land price in a significant way. The key question is whether the dynamic responses to a housing demand shock, without relying on an extremely high replacement ratio of income for unemployed workers, can account for not only the observed persistent fluctuations in the standard macroeconomic variables but also the observed high volatility of labor market variables. The answer is provided in Figure 2, where the estimated impulse responses from our DSGE model are consistent with the stylized facts evinced by the BVAR. According to the posterior mode estimate, the housing demand shock explains up to $20.24 \%$ of unemployment fluctuation in the DSGE model, a magnitude that is very similar to the $19.36 \%$ contribution from a shock to the land price in the BVAR.

Equally important is our finding that the dynamic responses to a housing demand shock can account for the observed high Shimer volatility ratio. In our data, the Shimer volatility ratio is 25.34. Simulating the artificial data of the same sample length as our data from the estimated DSGE model with housing demand shocks, we compute the Shimer volatility ratio for each sequence of simulated data and obtain a mean value of 22.58. The magnitude of this ratio is remarkably similar to the data. Thus, the labor channel, reinforced by the credit channel, provides a statistically and economically significant mechanism that explains not only persistent comovements between the land price and the unemployment rate but also the observed large volatility in the labor market.

\section{Related Literature}

Our work draws on two strands of literature: one on financial frictions and the other on labor-market frictions. Since the recent recession, there has been a large and rapidly growing strand of literature on the role of financial frictions 
and asset prices in macroeconomic fluctuations within the general equilibrium framework. The literature is too extensive to discuss adequately. A partial list includes Iacoviello (2005), Iacoviello and Neri (2010), Del Negro et al. (2010), Favilukis et al. (2010), Hall (2011a), Jermann and Quadrini (2012), Liu et al. (2013), Liu and Wang (2014), and Christiano et al. (2014) (see Gertler and Kiyotaki (2010) for a survey). This literature typically builds on the financial accelerator framework originally studied by Kiyotaki and Moore (1997) and Bernanke et al. (1999).

The recent literature on labor-market frictions is also too large to list exhaustively. Examples are Gertler et al. (2008), Gertler and Trigari (2009), Lubik (2009), Blanchard and Galí (2010), Justiniano and Michelacci (2011), Christiano et al. (2011), Galí et al. (2012), and Christiano et al. (2013). Recent studies on potential links between financial factors and unemployment fluctuations include Davis et al. (2010), Hall (2011b), Monacelli et al. (2011), Petrosky-Nadeau and Wasmer (2013), Petrosky-Nadeau (2014), and Miao et al. (2015).

The recent studies by Mian et al. (2013) and Mian and Sufi (2014) present evidence that falling house prices during the Great Recession have substantially impaired households' balance sheets and thus contributed to the rise in the unemployment rate through consumption reductions. On the other hand, Chaney et al. (2012) provide evidence supporting the importance of U.S. corporate firms' real-estate value in affecting their investment. While we follow Chaney et al. (2012) by focusing on firms' behavior, the endogenous real wage rigidity in our paper stems from the household's decision about consumption, as emphasized by Mian et al. (2013) and Mian and Sufi (2014).

Our paper contributes to the literature by providing a first study that integrates the housing market and the labor market within the DSGE framework and uses the estimated structural model to account for the strong connections between land-price dynamics and large unemployment fluctuations that we observe in the data.

\section{The Model}

The economy is populated by three types of agents: households, capital producers, and firms. Each type has a continuum of agents. The representative capital producer (i.e., the capitalist) derives utility from consuming a final good produced by firms. The capitalist has access to an investment technology that transforms consumption goods into capital goods. The capitalist finances expenditures by both internal and external funds. Limited contract enforcement implies that the capitalist's borrowing capacity is constrained by the value of collateral assets - the land and capital stocks held by the capitalist. The capitalist owns all firms. A firm in an employment match hires one worker from the representative household and rents capital and land from the representative capitalist to produce the final good.

The representative household consumes both goods and housing services (by owning the land) and saves in the risk-free bond market. There is a continuum of workers within the representative household. A fraction of workers is employed 
and the other fraction (unemployed workers) searches for jobs in the frictional labor market. Firms post vacancies at a fixed cost. An employment match is formed according to a matching technology that combines searching workers and job vacancies to "produce" new employment matches.

\subsection{Households}

Similar to Piazzesi et al. (2007), the representative household has nonseparable preferences between consumption of goods and housing services, with the utility function

$$
E \sum_{t=0}^{\infty} \beta_{h}^{t}\left[\frac{\left(L_{h t}^{\varphi_{L t}}\left(C_{h t}-\eta_{h} C_{h t-1}\right) / Z_{t}^{p}\right)^{1-\gamma}}{1-\gamma}-\chi g\left(h_{t}\right) N_{t}\right], g\left(h_{t}\right)=\frac{h_{t}^{1+\nu}}{1+\nu}
$$

where $E[\cdot]$ is the expectation operator, $C_{h t}$ denotes consumption, $L_{h t}$ denotes the household's land holdings, $h_{t}$ denotes labor hours (the intensive margin), and $N_{t}$ denotes employment (the extensive margin) - the fraction of household members who is employed.

The parameter $\beta_{h} \in(0,1)$ denotes the subjective discount factor, $\chi$ denotes the weight on labor disutility, $\eta_{h}$ measures the household's habit persistence, and $\gamma$ is the risk aversion parameter. Since consumption of goods grows over time while land supply and employment do not, we scale consumption by the growth factor $Z_{t}^{p}$ (i.e., the permanent component of the technology shock) to obtain balanced growth. The variable $\varphi_{L t}$ is a housing demand shock that follows the stochastic process

$$
\ln \varphi_{L t}=\left(1-\rho_{L}\right) \ln \varphi_{L}+\rho_{L} \ln \varphi_{L, t-1}+\varepsilon_{L t},
$$

where $\rho_{L} \in(-1,1)$ is the persistence parameter and $\varepsilon_{L t}$ is a serially independent normal random process with mean zero and variance $\sigma_{L}^{2}$.

In the limiting case with $\gamma=1$, the utility function (1) reduces to the standard separable preferences

$$
E \sum_{t=0}^{\infty} \beta_{h}^{t}\left[\ln \left(C_{h t}-\eta_{h} C_{h t-1}\right)+\varphi_{L t} \ln L_{h t}-\chi g\left(h_{t}\right) N_{t}\right] .
$$

In theory, nonseparability $(\gamma>1)$ allows housing demand shocks to directly affect the household's marginal utility and thus reservation real wages, as we discuss in Section 3.5. This direct effect, however, turns out to be empirically unimportant. What is important, as we show in Section 7.2 is that nonseparable preferences and high risk aversion $(\gamma>1)$ allow a housing demand shock to drive large fluctuations of the land price, which in turn gives both the credit channel and the labor channel the opportunity to be active in the model.

The household is initially endowed with $L_{h,-1}$ units of land and has no initial saving. The household chooses consumption $\left\{C_{h t}\right\}$, land holdings $\left\{L_{h t}\right\}$, and 
saving $\left\{B_{h t}\right\}$ to maximize the utility function in (1) subject to the sequence of budget constraints

$C_{h t}+\frac{B_{h t}}{R_{t}}+Q_{l t}\left(L_{h t}-L_{h, t-1}\right)=B_{h t-1}+W_{t} h_{t} N_{t}+b Z_{t}^{p}\left(1-N_{t}\right)-T_{t}, \quad \forall t \geq 0$,

where $B_{h t}$ denotes the savings, $R_{t}$ denotes the risk-free interest rate, $Q_{l t}$ denotes the land price, $W_{t}$ denotes the wage rate, $N_{t}$ denotes the fraction of workers employed, $b$ denotes the unemployment benefit, and $T_{t}$ denotes lump-sum taxes. We follow Hall (2005) and scale the unemployment benefit by $Z_{t}^{p}$, so that the unemployment benefit relative to labor income remains stationary.

The household does not unilaterally choose $h_{t}$ or $N_{t}$. Instead, as we describe in Sections 3.3 and 3.5. these variables are determined in the labor market equilibrium with search and matching frictions.

\subsection{Capitalists}

The representative capitalist has the utility function

$$
E \sum_{t=0}^{\infty} \beta_{c}^{t} \ln \left(C_{c t}-\eta_{c} C_{c t-1}\right)
$$

where $\beta_{c} \in(0,1)$ denotes the capitalist's subjective discount factor, $C_{c t}$ denotes consumption, and $\eta_{c}$ is the habit persistence parameter.

The capitalist is initially endowed with $K_{-1}$ units of capital and $L_{c,-1}$ units of land, with no initial debt. The capitalist faces the flow-of-funds constraint

$C_{c t}+Q_{l t}\left(L_{c t}-L_{c, t-1}\right)+I_{t}+\Phi\left(e_{t}\right) K_{t-1}+B_{c, t-1}=\frac{B_{c t}}{R_{t}}+R_{k t} e_{t} K_{t-1}+R_{l t} L_{c, t-1}+\Pi_{t}$,

where $L_{c t}, I_{t}, e_{t}, K_{t}, B_{c t}, R_{k t}, R_{l t}$, and $\Pi_{t}$ denote the capitalist's land holdings, investment, the capacity utilization rate, the end-of-period capital stock, the debt level, the rental rate of capital, the rental rate of land, and dividends collected from firms, respectively. The dividend income includes firms' flow profits net of labor costs and vacancy posting costs. For tractability, we assume that residential land and commercial land in our model are perfect substitutes and hence have the same price. This assumption is a reasonable approximation to the U.S. economy because the commercial land price and the residential land price are highly correlated ${ }^{3}$

The cost of capacity utilization $\Phi(e)$ is an increasing and convex function given by

$$
\Phi\left(e_{t}\right)=\gamma_{1}\left(e_{t}-1\right)+\frac{\gamma_{2}}{2}\left(e_{t}-1\right)^{2},
$$

\footnotetext{
${ }^{3}$ For example, the correlation between the seasonally adjusted quarterly series of the Federal Reserve's commercial land price index and our constructed residential land price data is above 0.9. This finding is further confirmed by Nichols et al. (2013), who construct residential and commercial land price indices for $23 \mathrm{MSAs}$ and national aggregates and find that the two land price series comove closely during their sample period from 1995 to 2011. Our results as well as our key mechanism would be robust to using either of these land price series.
} 
where the slope and curvature parameters, $\gamma_{1}$ and $\gamma_{2}$, are both non-negative.

The capitalist finances consumption, acquisitions of new land, and investment expenditures by both internal funds and external credit. We assume that $\beta_{c}<\beta_{h}$ and the amount the capitalist can borrow is limited by a fraction of their collateral value. This assumption ensures that the borrowing constraint for the capitalist binds in a neighborhood of the deterministic steady state.

Denote by $Q_{k t}$ the shadow price of capital (i.e., Tobin's q). The collateral constraint is given by

$$
B_{c t} \leq \xi_{t} \mathrm{E}_{t}\left(\omega_{1} Q_{l, t+1} L_{c t}+\omega_{2} Q_{k, t+1} K_{t}\right),
$$

where $\omega_{1}$ and $\omega_{2}$ are the parameters that determine the weight of land and capital in the collateral value. The collateral constraint here is motivated by the limited contract enforcement problem emphasized by Kiyotaki and Moore (1997). If the capitalist fails to repay the loan, the lender can seize the collateral. Since liquidation is costly, the lender can recoup up to a fraction $\xi_{t}$ of the value of collateral assets. We interpret $\xi_{t}$ as a collateral shock and assume that it follows the stochastic process

$$
\ln \xi_{t}=\left(1-\rho_{\xi}\right) \ln \xi+\rho_{\xi} \ln \xi_{t-1}+\varepsilon_{\xi t},
$$

where $\rho_{\xi} \in(-1,1)$ is the persistence parameter and $\varepsilon_{\xi t}$ is a serially independent normal random process with mean zero and variance $\sigma_{\xi}^{2}$.

The capitalist has access to an investment technology that transforms consumption goods into productive capital. In particular, given the beginning-ofperiod capital stock $K_{t-1}$, the capitalist can transform $I_{t}$ units of consumption goods into $K_{t}$ units of new capital. Thus, the law of motion of the capital stock is given by

$$
K_{t}=(1-\delta) K_{t-1}+\left[1-\frac{\Omega}{2}\left(\frac{I_{t}}{I_{t-1}}-\gamma_{I}\right)^{2}\right] I_{t},
$$

where $\delta \in(0,1)$ denotes the depreciation rate of capital, $\Omega>0$ is the adjustment cost parameter, and $\gamma_{I}$ denotes the steady-state growth rate of investment.

\subsection{The labor market}

At the beginning of period $t$, there are $u_{t}$ unemployed workers searching for jobs and there are $v_{t}$ vacancies posted by firms. The matching technology is described by the Cobb-Douglas function

$$
m_{t}=\varphi_{m t} u_{t}^{a} v_{t}^{1-a},
$$

where $a \in(0,1)$ is the elasticity of job matches with respect to the number of searching workers. The variable $\varphi_{m t}$ is an exogenous matching efficiency shock that follows the stochastic process

$$
\ln \varphi_{m t}=\left(1-\rho_{m}\right) \ln \varphi_{m}+\rho_{m} \ln \varphi_{m, t-1}+\varepsilon_{m t},
$$


where $\rho_{m} \in(-1,1)$ is the persistence parameter and $\varepsilon_{m t}$ is a serially independent normal random process with mean zero and variance $\sigma_{m}^{2}$.

The probability that an open job vacancy is matched with a searching worker, the job filling rate, is given by

$$
q_{t}^{v}=\frac{m_{t}}{v_{t}}
$$

The probability that an unemployed and searching worker is matched with an open job vacancy, the job finding rate, is given by

$$
q_{t}^{u}=\frac{m_{t}}{u_{t}} .
$$

Before matching takes place, a fraction $\rho$ of workers lose their jobs. The number of workers who survive job separations is $(1-\rho) N_{t-1}$. Thus, the number of unemployed workers searching for jobs in period $t$ is given by

$$
u_{t}=1-(1-\rho) N_{t-1}
$$

where we have assumed full labor-force participation. After matching takes place, the number of jobless workers who find jobs is $m_{t}$. Thus, aggregate employment evolves according to the law of motion

$$
N_{t}=(1-\rho) N_{t-1}+m_{t} .
$$

Following Blanchard and Galí (2010), we assume that newly hired workers start working within the same period. Thus, the number of productive workers in period $t$ is given by $N_{t}$.

At the end of period $t$, the number of unemployed workers equals those searching workers who fail to find a match. Thus, the unemployment rate is given by

$$
U_{t}=u_{t}-m_{t}=1-N_{t} .
$$

\subsection{Firms}

A firm can produce only if it can be successfully matched with a worker ${ }^{4} \mathrm{~A}$ firm with a worker rents capital $k_{t}$ and land $l_{c t}$ from the capitalist. It produces the final consumption good using the technology

$$
y_{t}=Z_{t}^{1-\alpha+\phi \alpha}\left(l_{c t}^{\phi} k_{t}^{1-\phi}\right)^{\alpha} h_{t}^{1-\alpha},
$$

where $y_{t}$ is output, the parameters $\phi \in(0,1)$ and $\alpha \in(0,1)$ measure input elasticities, and $Z_{t}$ is a technology shock with a permanent component $Z_{t}^{p}$ and

\footnotetext{
${ }^{4}$ We show in Supplemental Appendix B that this setup is equivalent to an alternative setup with one large representative firm.
} 
a transitory (stationary) component $Z_{t}^{m}$ such that $Z_{t}=Z_{t}^{p} Z_{t}^{m}$. The permanent component $Z_{t}^{p}$ follows the stochastic process

$$
Z_{t}^{p}=Z_{t-1}^{p} \lambda_{z t}, \quad \ln \lambda_{z t}=\left(1-\rho_{z p}\right) \ln \lambda_{z}+\rho_{z p} \ln \lambda_{z, t-1}+\varepsilon_{z p, t} .
$$

The stationary component follows the stochastic process

$$
\ln Z_{t}^{m}=\left(1-\rho_{z m}\right) \ln Z^{m}+\rho_{z m} \ln Z_{t-1}^{m}+\varepsilon_{z m, t} .
$$

The parameter $\lambda_{z}$ is the steady-state growth rate of $Z_{t}^{p}$, and the parameters $\rho_{z p}$ and $\rho_{z m}$ measure the degrees of persistence of $\lambda_{z t}$ and $Z_{t}^{m}$. The innovations $\varepsilon_{z p, t}$ and $\varepsilon_{z m, t}$ are serially independent mean-zero normal random processes with standard deviations given by $\sigma_{z p}$ and $\sigma_{z m}$.

Denote by $J_{t}^{F}$ the value of a new employment match. A firm matched with a worker obtains profits in the current-period production. In the next period, if the match survives (with probability $1-\rho$ ), the firm continues to receive the match value; otherwise, the firm receives the value of an open job vacancy $\left(V_{t}\right)$. Thus, the match value is given by

$$
J_{t}^{F}=\pi_{t}-W_{t} h_{t}+E_{t} \frac{\beta_{c} \Lambda_{c t+1}}{\Lambda_{c t}}\left[(1-\rho) J_{t+1}^{F}+\rho V_{t+1}\right],
$$

where $\pi_{t}$ denotes profit prior to wage payments, $W_{t}$ denotes the wage rate, $h_{t}$ denotes the hours worked, and $\Lambda_{c t}$ denotes the marginal utility of consumption for the representative capitalist who owns the firm.

The profit $\pi_{t}$ prior to wage payments is obtained by solving the optimizing problem

$$
\pi_{t}=\max _{k_{t}, l_{c t}} Z_{t}^{1-\alpha+\phi \alpha}\left(l_{c t}^{\phi} k_{t}^{1-\phi}\right)^{\alpha} h_{t}^{1-\alpha}-R_{k t} k_{t}-R_{l t} l_{c t},
$$

where the rental prices $R_{k t}$ and $R_{l t}$ are taken as given.

If the firm posts a job vacancy for hiring a worker, it pays the cost $\kappa Z_{t}^{p}$. Note that we have followed Hall (2005) to scale the vacancy posting cost by $Z_{t}^{p}$ to keep stationary the ratio of this cost to output. If the vacancy is filled (with probability $q_{t}^{v}$ ), then the firm obtains the value $J_{t}^{F}$. Otherwise, the firm carries the vacancy to the next period. The value of an open job vacancy $V_{t}$ satisfies the Bellman equation

$$
V_{t}=-\kappa Z_{t}^{p}+q_{t}^{v} J_{t}^{F}+\left(1-q_{t}^{v}\right) E_{t} \frac{\beta_{c} \Lambda_{c, t+1}}{\Lambda_{c t}} V_{t+1} .
$$

Free entry implies that $V_{t}=0$ for all $t$. It follows from equation 23) that

$$
J_{t}^{F}=\frac{\kappa Z_{t}^{p}}{q_{t}^{v}} .
$$

231 This condition characterizes optimal vacancy posting decisions. 


\subsection{Nash bargaining}

When a job match is formed, a firm and a worker bargain over wages and hours in a Nash bargaining game. The worker's surplus is the difference between the value of employment and the value of unemployment. The firm's surplus is just the match value $J_{t}^{F}$ because the value of an open vacancy $V_{t}$ is driven to zero by free entry. We have specified the firm's match value in the preceding section. We now describe the worker's value functions.

If employed, the worker receives a wage payment in the current period, although suffers disutility from working. In the next period, the worker may lose the job with probability $\rho$ and cannot find a new job with probability $1-q_{t+1}^{u}$ (recall that $q^{u}$ is the job finding rate). In that event, the worker obtains the present value of unemployment (denoted by $J_{t}^{U}$ ). Otherwise, the worker continues to have a job and receives the employment value (denoted by $\left.J_{t}^{W}\right)$. Specifically, the value of employment is given by

$J_{t}^{W}=W_{t} h_{t}-\frac{\chi g\left(h_{t}\right)}{\Lambda_{h t}}+E_{t} \frac{\beta_{h} \Lambda_{h, t+1}}{\Lambda_{h t}}\left[\left(1-\rho\left(1-q_{t+1}^{u}\right)\right) J_{t+1}^{W}+\rho\left(1-q_{t+1}^{u}\right) J_{t+1}^{U}\right]$,

where $\Lambda_{h t}$ denotes the marginal utility of consumption for households.

An unemployed worker receives the flow benefit of unemployment $b Z_{t}^{p}$ from the government. In the beginning of the next period, the unemployed finds a job with probability $q_{t+1}^{u}$ and obtains the present value of employment. Otherwise, he remains unemployed. The value of unemployment is given by

$$
J_{t}^{U}=b Z_{t}^{p}+E_{t} \frac{\beta_{h} \Lambda_{h, t+1}}{\Lambda_{h t}}\left[q_{t+1}^{u} J_{t+1}^{W}+\left(1-q_{t+1}^{u}\right) J_{t+1}^{U}\right] .
$$

The firm and the worker bargain over wages and hours. The Nash bargaining problem they face is given by

$$
\max _{W_{t}, h_{t}}\left(J_{t}^{W}-J_{t}^{U}\right)^{\frac{\vartheta_{t}}{1+\vartheta_{t}}}\left(J_{t}^{F}\right)^{\frac{1}{1+\vartheta_{t}}},
$$

where $\vartheta_{t}$ represents a time-varying bargaining weight for the workers and it follows the stochastic process

$$
\ln \vartheta_{t}=\left(1-\rho_{\vartheta}\right) \ln \vartheta+\rho_{\vartheta} \ln \vartheta_{t-1}+\varepsilon_{\vartheta t},
$$

where $\rho_{\vartheta}$ measures the persistence of the bargaining shock and $\varepsilon_{\vartheta t}$ is a serially independent normal random process with mean zero and variance $\sigma_{\vartheta}^{2}$.

It is straightforward to show that the bargaining solutions for the wage rate and labor hours satisfy the following two equations:

$W_{t}=\frac{\chi g\left(h_{t}\right) / h_{t}}{\Lambda_{h t}}+b Z_{t}^{p} / h_{t}+\frac{1}{h_{t}}\left[\vartheta_{t} J_{t}^{F}-\mathrm{E}_{t} \frac{\beta_{h} \Lambda_{h, t+1}}{\Lambda_{h t}}\left((1-\rho)\left(1-q_{t+1}^{u}\right) \vartheta_{t+1} J_{t+1}^{F}\right)\right]$,

and

$$
\frac{\chi g^{\prime}\left(h_{t}\right)}{\Lambda_{h t}}=\frac{\partial y_{t}}{\partial h_{t}} .
$$



that

$$
\begin{gathered}
B_{c t}=B_{h t} \equiv B_{t}, \\
L_{c t}+L_{h t}=1, \\
e_{t} K_{t-1}=N_{t} k_{t}, \\
C_{t}+I_{t}+\Phi\left(e_{t}\right) K_{t-1}+\kappa Z_{t}^{p} v_{t}=Y_{t},
\end{gathered}
$$

where $B_{t}$ denotes the equilibrium level of debt for capitalists, $C_{t} \equiv C_{h t}+C_{c t}$ denotes aggregate consumption, and $Y_{t}$ denotes aggregate output. We normalize the supply of land to 1 . Aggregate output is given by

$$
Y_{t}=Z_{t}^{1-\alpha+\phi \alpha}\left(l_{c t}^{\phi} k_{t}^{1-\phi}\right)^{\alpha} h_{t}^{1-\alpha} N_{t}=\left[\left(Z_{t} L_{c, t-1}\right)^{\phi}\left(e_{t} K_{t-1}\right)^{1-\phi}\right]^{\alpha}\left(Z_{t} h_{t} N_{t}\right)^{1-\alpha},
$$

The last equation implies that the value of the marginal product of hours is real business cycle literature. The condition obtains because the correct measure of the cost of hours to the firm is the marginal rate of substitution. Unlike the real business cycle literature, however, the wage rate is no longer allocative for 3.6. The government

The government finances unemployment benefit payments through lumpsum taxes imposed on households. We assume that the government balances the budget in each period so that$$
\text { here we have imposed the land rental market clearing condition that } L_{c, t-1}=
$$
$l_{c t} N_{t}$.

A search equilibrium consists of sequences of prices $\left\{Q_{l t}, Q_{k t}, R_{t}, R_{k t}, R_{l t}\right\}$, wages $\left\{W_{t}\right\}$, allocations $\left\{C_{h t}, B_{h t}, L_{h t}\right\}$ for households, allocations $\left\{C_{c t}, B_{c t}, L_{c t}, K_{t}, I_{t}, e_{t}\right\}$ for capitalists, allocations $\left\{y_{t}, k_{t}, l_{c t}, h_{t}\right\}$ for each firm, and labor market variables $\left\{m_{t}, u_{t}, v_{t}, N_{t}, q_{t}^{u}, q_{t}^{v}\right\}$, such that (i) taking all prices and wages as given, households' allocations maximize their utility, (ii) taking all prices and wages as given, capitalists' allocations maximize their utility, (iii) taking all prices and wages as given, allocations for each firm with a job match maximize the firm's profit, (iv) new matches are formed based on the matching technology, with wages and labor hours determined from the bilateral bargaining between firms and workers, and (v) the land market, the capital market, the bond market, and the goods market all clear. 


\section{Estimation}

We fit the DSGE model to U.S. time series data. To this end, we solve the model based on log-linearized equilibrium conditions around the deterministic steady state, in which the collateral constraint is binding $5^{5}$ The model with six shocks is then confronted with six quarterly U.S. time series from 1975Q1 to 2015Q3. These series include the real land price, per capita real consumption, per capita real investment, the job vacancy rate, the unemployment rate, and per capita total hours. To be consistent with the model specification, we measure consumption expenditures as the sum of nondurable consumption and non-housing services and we measure investment expenditures as the sum of investment spending on equipment and intellectual property and consumer spending on durable goods. We provide a detailed description in Supplement Appendix D of the time series data, the shocks in the model, and the measurement equations.

We use the Bayesian method to estimate the model. Our estimation reveals that shocks to housing demand drive almost all the fluctuations in the land price. Since our goal is to study the dynamic link between the land price and the unemployment rate, our subsequent discussions revolve around understanding the macroeconomic and labor-market effects of a shock to housing demand 6 We provide a detailed description in Supplemental Appendix E of the prior distributions for the model parameters and discuss in Supplemental Appendix F our estimation strategies and some computation issues.

Some parameters are difficult to identify by the model. We fix the values of these parameters prior to estimation to match steady-state observations. Table 1 displays the targeted steady state values and the calibrated parameters. We discuss in Supplement Appendix E the details of what these parameters are and how they are calibrated. Here we highlight two steady-state targets and one calibrated parameter. The first target is the steady-state replacement ratio, which we calibrate to $\frac{b}{W}=0.75$ following Christiano et al. (2013). Our results hold if the replacement ratio is reduced to 0.4, similar to the calibration in Ravenna and Walsh (2008) and Hall (2005). The second steady-state target is the share of capitalists' consumption in aggregate consumption. We target this share at $6 \%$, which is consistent with the U.S. data in which the

\footnotetext{
${ }^{5}$ In Supplemental Appendix C, we provide a complete description of stationary equilibrium conditions, steady state equations, and log-linearized equilibrium conditions.

${ }^{6}$ As we have discussed in the introduction section, we do not interpret a housing demand shock as a purely exogenous shift in the representative household's taste for housing services. This shock, similar to TFP shocks and other "structural" shocks in the macro literature, is a reduced-form representation of exogenous shifts at the micro level or other deeper sources of fluctuations that are outside of our model (see Liu et al. (2013) for a related discussion). Our contribution is to show that any shock that shifts the marginal utility of housing services and drives fluctuations in the land price can have a quantitatively important impact on the labor market through the labor channel that we discuss below. This finding is new and important. We further show that in the class of DSGE models with collateral constraints similar to the one considered in the paper, other shocks such as a TFP shock do not influence labor market variables with a similar magnitude as does the housing demand shock.
} 
average ratio of corporate profits to personal consumption expenditures from 1950Q1 to 2015Q3 is 7.72\% while the average ratio of net dividends to personal consumption expenditures during the same period is $2.86 \%$. We fix the risk aversion parameter $\gamma$ at 2 following Kocherlakota (1996) and Lucas Jr. (2003). This value of $\gamma$ implies non-separable preferences for the household. We discuss in Section 7.2 the consequences allow the household preferences to be separable (i.e., $\gamma=1$ ).

Table 2 reports the posterior mode and the $90 \%$ probability interval of each estimated model parameter (the last three columns), along with the prior distributions (from the second to fourth columns) for comparison. The table shows that capitalists have a much stronger habit formation than households $(0.996$ vs. 0.166). Strong habit formation for capitalists helps smooth their consumption and amplify the fluctuation of investment following a shock to housing demand. Since firms are owned by capitalists, moreover, strong habit formation implies high volatility in the stochastic discount factor for firms, which generates large fluctuations in the value of a new employment match. Fluctuations in the match value are the key to generating large volatilities in job vacancies and unemployment.

The estimated value of the investment adjustment cost parameter $(\Omega=$ 0.114 ) is very small compared to the DSGE literature without financial frictions. A small adjustment cost parameter is necessary to obtain a large fluctuation of investment. It also implies low volatility in the shadow price of capital (Tobin's q). Thus, the collateral channel works mainly through interactions between debt and land value. Consistent with this finding, the estimated weight on capital value in the collateral constraint is considerably smaller than that on land value $\left(\omega_{2}=0.01\right.$ vs. the normalized value of $\left.\omega_{1}=1\right)$.

The estimated parameter values for the capacity utilization function imply a large elasticity of the capital rental rate with respect to capacity utilization (the elasticity $\gamma_{2} / \gamma_{1}$ is 11.5). Since the capital rental rate does not fluctuate much in our model, the large elasticity implies a small fluctuation of capacity utilization. Thus, the model does not rely on variable capacity utilization to fit the data.

The curvature parameter of the disutility function of labor hours, $\nu$, is estimated to be almost zero. This finding, however, does not contradict the microeconomic evidence of a small Frisch elasticity of labor hours. In particular, in a model with credit constraints and adjustment costs, there is in general no direct mapping from the preference parameter $\nu$ to the intertemporal labor supply elasticity (Keane and Rogerson, 2012). In our model, the small value of $\nu$ allows necessary fluctuations in labor hours (the intensive margin) to prevent the model from "overshooting" the volatility of unemployment. We discuss the overshooting phenomenon in Section 6.2 .

Given the above calibrated and estimated parameters, the remaining model parameters such as $\delta, \beta_{h}, \beta_{c}, \phi, \lambda_{z}$, and $\varphi_{L}$ can be pinned down by solving the steady state. The estimated values, as documented in Table 3 of Supplement Appendix E, are broadly in line with those obtained in the literature (Iacoviello, 2005: Liu et al. 2013). 
Table 2 also reports the prior and posterior distributions of shock parameters. We follow the DSGE literature and assume that the prior for the persistence parameters follows the beta distribution and the prior for the volatility parameters follows the inverse-gamma distribution. We select the hyperparameters for these prior distributions to obtain a reasonably wide $90 \%$ probability interval for each parameter. The posterior mode estimates indicate that the housing demand shock process is most persistent and volatile. This shock process, as we show in Section 5 , is most important in driving the persistent comovement between the land price and the unemployment rate as well as large fluctuations of unemployment.

\section{Dynamic interactions between the land price and the labor market}

We now use the estimated model to assess the empirical importance of dynamic interactions between the land price and labor-market variables. We begin with a discussion of the macroeconomic effects of land-price dynamics. We then analyze how the labor market fluctuates with changes in the land price. We conclude by quantifying the large volatility of labor-market variables.

Figure 2 (the right column) and Figure 3 report the impulse responses of several macroeconomic and labor market variables to a negative housing demand shock. Error bands for impulse responses are generated according to the likelihood-based methodology proposed by Zha (1999) and Sims and Zha (1999). The shock leads to a persistent decline in the land price. The decline in the land value tightens capitalists' borrowing capacity, which in turn reduces their land acquisition and business investment.

As investment falls, future capital stocks decline and future marginal productivity of employment (i.e., the output value of an additional worker) also declines. This reduces the present value of a new employment match. Firms respond by posting fewer job vacancies. Consequently, the job finding rate for unemployed workers declines, leading to an increase in the unemployment rate as the land price falls. Judging from the error bands, the impulse responses in Figure 2 (the right column) and Figure 3 are all precisely estimated.

To see how well our structural model fits to the data, we reproduce in the left column of Figure 2 the estimated dynamic responses of the land price and three key labor-market variables to a negative housing demand shock in the DSGE model (asterisk lines) against the $90 \%$ probability bands for the impulse responses obtained from the BVAR (shaded areas). We estimate the BVAR using seven time-series data, including the six variables used for estimating the DSGE model along with real wages. We use the BVAR impulse responses to characterize the stylized facts about the dynamic responses of these variables to a shock that moves the land price. We focus on the impulse responses of the land price, total hours, unemployment, and real wages 7 To be conceptually

${ }^{7}$ We show a full set of impulse responses from both BVAR and DSGE models in Figure 1 of Supplemental Appendix A. In Section 6.3 we discuss how the out-of-sample prediction of 
consistent with the DSGE model, all seven variables are in log level and the BVAR is estimated with a lag length of three and with the land price ordered last to control for all other shocks that may have a contemporaneous effect on the land price 8

By comparing the left and right columns of Figure 2 one can see that the estimated DSGE results fit the stylized facts surprisingly well in both dimensions: comovement and volatility. Not only does the estimated DSGE model generate the observed comovements between the land price and the standard macroeconomic and labor-market variables, but more important is the model's ability to generate the observed large volatility in the labor market. Given how restrictive our DSGE model is relative to the BVAR, these results are remarkable.

A housing demand shock explains almost all fluctuations of the land price and at the same time causes considerable volatility of unemployment. According to the DSGE median estimate of variance decomposition, the housing demand shock accounts for $20.46 \%$ of the overall unemployment fluctuations at the one-year horizon with a $90 \%$ probability interval of $[16.00 \%, 25.67 \%]$. At the six-year horizon, its impact remains strong, accounting for $18.29 \%$ with a $90 \%$ probability interval of $[12.78 \%, 25.11 \%]$. These estimated contributions of a housing demand shock in the DSGE model are remarkably similar to those obtained from the BVAR. According to the BVAR median estimate of variance decomposition, a shock to the land price accounts for $15.88 \%$ of the overall unemployment fluctuation at the one-year horizon with a $90 \%$ probability interval of $[5.45 \%, 30.46 \%]$; the contribution stays significant at the six-year horizon ( $18.19 \%$ with a $90 \%$ probability interval of $[5.80 \%, 38.39 \%])$.

In addition to the variance decomposition results discussed above, the estimated counterfactual history of the land price and the unemployment rate shed light on the Great Recession episode. In the Great Recession, the crash in land prices was followed by a surge in unemployment. In particular, the land price fell by about $90 \%$ from its pre-recession peak level and the unemployment rate rose by about 5 percentage points. In the subsequent recovery, the steady increases in land prices were associated with steady declines in the unemployment rate. Figure 4 shows the actual time-series paths of the land price and the unemployment rate (dark thick lines).

To examine the extent to which variations in housing demand have contributed to the fall in the land price and the rise in unemployment, we display in Figure 4 the counterfactual paths of the two variables implied by the esti-

real wage dynamics from the DSGE model compares with the fact stylized from the BVAR.

${ }^{8}$ The results, however, are robust to other orderings. In earlier drafts of this paper we order the land price first and obtain similar results. This ordering, however, is not a priori appealing. We thank the referee for this insightful comment. The prior we use follows closely Sims and Zha (1998) with the prior hyperparameter values set at $\lambda_{1}=\lambda_{2}=\lambda_{3}=1, \lambda_{4}=1.2$, and $\mu_{5}=\mu_{6}=3$ according to their notation. The hyperparameters $\mu_{5}$ and $\mu_{6}$ allow for the presence of cointegration. Since the land price comoves strongly with other variables, this component of cointegration prior is essential for capturing the data dynamics. By the marginal data density (marginal likelihood) criterion, the data favors the lag length being three over longer lag lengths such as four or five. 
mated model driven by the estimated housing demand shocks alone (the light thin lines) ${ }^{9}$ As expected, almost all declines in the land price in the Great Recession period and the subsequent increases are attributable to housing demand shocks, with the counterfactual path of land prices tracking the actual data closely. The same housing demand shocks generated an increase in the unemployment rate of about 3.5 percentage points during the recession period and a decline of about 2 percentage points during the recovery. This historical decomposition result for the Great Recession and recovery periods and the previous average variance decomposition result both suggest that shocks driving large fluctuations of land prices also have quantitatively important impact on the unemployment rate.

Shimer (2005) emphasizes a special statistic for measuring the volatility of the labor market: the ratio of the standard deviation of labor market tightness to the standard deviation of aggregate labor productivity. To compute the Shimer volatility ratio, we simulate model parameters from the posterior distribution; for each set of simulated parameters, we use the model to generate a sequence of housing demand shocks and a time series of all the variables with a sample length equal to that in the actual data. We repeat this process 100,000 times. Following Shimer (2005) and Christiano et al. (2013), we first HP-filter both the simulated series and the actual data; we then compute the Shimer volatility ratio. For the data, the ratio is 25.34. For the model, the mean estimate of the ratio is 22.58 with a $90 \%$ probability interval of $[19.12,26.36]$. Thus, a housing demand shock is capable of generating the Shimer volatility ratio with a magnitude similar to that in the data ${ }^{10}$

In summary, the estimated impulse responses, variance decompositions, and historical decompositions, as well as the computed Shimer volatility ratio, evince the model's ability of accounting for the dynamic interactions between land prices and unemployment as well as the large volatility of unemployment.

\section{Understanding the economic mechanism}

In this section we analyze the economic mechanism that drives our estimated results. We identify two key channels for the transmission and amplification of housing demand shocks to the aggregate economy and the labor market: the credit channel and the labor channel.

\subsection{The credit channel}

As shown in both the data and our structural estimation (Figures 2 and 3), the fall of the land price is driven by a negative housing demand shock. Due

\footnotetext{
${ }^{9}$ The size of housing demand shocks during the Great Recession period is large with an average value of -1.92 , almost twice the standard deviation. Moreover, these negative shocks are persistent throughout this period.

${ }^{10}$ To reinforce the importace of this finding, we perform a similar exercise with data simulations generated by shocks other than housing demand. We find that the mean estimate of the Shimer volatility ratio is only 5.98 with a $90 \%$ probability interval of $[4.39,7.85]$.
} 
to the credit constraint, this fall directly reduces capitalists' land value and borrowing capacity, resulting in the fall of business investment (Liu et al., 2013).

We now illustrate the credit channel through which the value of a new employment match (or the match value) declines as a result of declining investment. Equations 21 and 222 imply that the match value $\left(J_{t}^{F}\right)$ is given by

$$
J_{t}^{F}=(1-\alpha) Z_{t}^{1-\alpha+\alpha \phi}\left(l_{c t}^{\phi} k_{t}^{1-\phi}\right)^{\alpha} h_{t}^{1-\alpha}-W_{t} h_{t}+E_{t} \frac{\beta_{c} \Lambda_{c t+1}}{\Lambda_{c t}}(1-\rho) J_{t+1}^{F} .
$$

The first term on the right-hand side is the marginal productivity of an employed worker. A decline in investment leads to a reduction in future capital stocks, which in turn leads to a reduction in future marginal productivity of an employed worker. For any given real wages and labor hours, the decline in future marginal productivity reduces the present value of a new match.

How the fall of the new employment value is transmitted into the labor market is illustrated in Figure 5. The figure plots the Beveridge curve (the inverse relation between job vacancies and unemployment derived from the matching function) and the job creation curve (the positive relation between job vacancies and unemployment derived from the free-entry condition). The Beveridge curve $(\mathrm{BC})$, derived from the matching function (11), implies that

$$
v=\left(\frac{\rho}{\varphi_{m}(1-\rho)} \frac{1-u}{u^{\alpha}}\right)^{\frac{1}{1-a}},
$$

where we have imposed the steady-state relations that $m=\rho N$ and $1-u=$ $(1-\rho) N$. The job creation curve (JCC) derived from the free-entry condition (24) implies that

$$
v=\left(\varphi_{m} \frac{J^{F}}{\kappa}\right)^{\frac{1}{a}} u
$$

where we have used the relation $q^{v}=\varphi_{m}\left(\frac{u}{v}\right)^{\alpha}$ derived from the definition of $q^{v}$ and the matching function. Thus, the slope of the JCC depends positively on the value of a new employment match and negatively on vacancy posting costs.

The intersection of the $\mathrm{BC}$ and JCC determines equilibrium job vacancies and unemployment. Consider the initial equilibrium at point $\mathrm{A}$, corresponding to the steady state. As discussed in the earlier part of this section, a fall of business investment in response to a negative housing demand shock causes the present value of a new employment match to fall. The decline of the match value $J_{t}^{F}$ rotates the job creation curve downward as shown in Figure 5 . The economy moves along the downward-sloping Beveridge curve to a new equilibrium, with fewer job vacancies and a higher unemployment rate (point B).

To assess the full impact of this credit channel on the labor market, we consider a counterfactual economy in which the amount of credit that capitalists can obtain does not vary with their land and capital value such that their borrowing capacity remains at the steady state level. By construction, therefore, the credit channel is muted. The dynamic responses of the key macroeconomic 
and labor-market variables to a negative housing demand shock in this counterfactual economy are displayed Figure 6, along with those for the estimated benchmark economy.

The figure shows starkly different impulse responses to a housing demand shock between the counterfactual economy (solid lines) and the estimated economy (asterisk lines). In the counterfactual economy, capitalists' borrowing capacity is not affected by the decline of land price driven by the housing demand shock. As land becomes cheaper, capitalists' effective resources available for purchasing investment goods actually rise. Thus, the counterfactual economy fails to generate business-cycle comovements because investment, output, and labor hours all rise whereas consumption (not shown) and the land price both decline. The effects on the value of a new employment match and thus on unemployment are muted by an expansion of output in the absence of the credit channel.

\subsection{The labor channel}

A negative shock to housing demand, through the credit channel, sparks off a simultaneous decline in the land price and business investment, which in turn reduces the value of a job match, discourages firms from posting vacancies for hiring new workers, and thus leads to higher unemployment. But a decline in business investment alone is insufficient to produce a significant rise in unemployment. The reason is that, without real-wage rigidities, a drop in the wage rate would partially offset the effects of lower investment on the match value. One prominent example is a negative stationary technology shock. As Figure 7 shows, this shock in the estimated model (solid lines) leads to a large decline in business investment but fails to produce a large increase in unemployment. The result is not surprising as it confirms the finding of Shimer (2005) and others. The intuition is that real wages fall considerably, blunting the shock's impact on unemployment.

A negative shock to housing demand is capable of generating large increases in unemployment through the labor channel - a second transmission route in our model that produces endogenous wage rigidities. We now explain how the labor channel works using the Nash bargaining solution for real wages in Equation $(29)$.

The labor channel works for housing demand shocks but not for other shocks such as technology shocks. A negative technology shock reduces the value of an employment match and the number of job vacancy postings. The decreased job finding rate raises the unemployment duration, which weakens the workers' bargaining position and reduces the equilibrium wage rate. As shown in (29), the wage rate decreases when the match value $\left(J_{t}^{F}\right)$ falls or when the unemployment duration $\left(1 / q_{t}^{u}\right)$ rises. A negative technology shock also reduces consumption, as shown in Figure 7. The resultant increase in households' marginal utility $\left(\Lambda_{h}\right)$ reduces the worker's reservation value $\chi g\left(h_{t}\right) / \Lambda_{h t}$. Consequently, the worker is willing to accept a lower wage offer. In equilibrium the decline in real wages limits firms' desire to contract employment, rendering the impact on unemployment small. 
The effects of a housing demand shock differ from those of a technology shock, with the difference stemming mainly from the household side. To be sure, a negative housing demand shock also raises the duration of unemployment with similar logics, although its impact works indirectly through the credit channel discussed in the preceding section. Unlike a negative technology shock, however, a negative housing demand shock makes land less desirable for households so that they prefer to increase consumption. This substitution effect is a direct consequence of the housing preference shock; it is absent under other shocks such as a technology shock. In the meantime, interactions between land price and business investment amplify the impact of a housing demand shock on the land price, leading to sharp declines in the land price. As the land value declines, households want to reduce consumption. This wealth effect, however, is partially offset by the substitution effect, resulting in small fluctuations in household consumption and marginal utility and leading to muted responses of workers' reservation value in the wage bargaining game. Unemployed workers therefore have less incentive to accept wage cuts, resulting in large fluctuations in unemployment and job vacancies.

As shown in Figure 7 the response of household marginal utility to a housing demand shock (the asterisk line) is an order of magnitude smaller than that to a technology shock (the solid line). Consequently, real wages do not change much following a housing demand shock. The endogenous wage rigidity generated through the labor channel allows housing demand shocks to generate large impact on the value of a job match and therefore helps generate large fluctuations in job vacancies and unemployment.

While wage rigidities are crucial to the dynamic link between land prices and unemployment, how labor hours per employed worker (the intensive margin) adjust to changes in housing demand plays another important but different role in determining the effectiveness of the labor channel on unemployment dynamics. To see this point, consider a counterfactual economy in which the supply of labor hours is inelastic so that equilibrium labor hours do not respond to any shocks. We compare the dynamic responses to a negative housing demand shock in this counterfactual economy to those in the estimated economy in Figure 6. In the counterfactual economy with inelastic supply of labor hours (dashed lines), the land price falls along with investment and output as in the estimated economy (asterisk lines). But both the match value and unemployment in the counterfactual economy overshoot the responses in the estimated economy. Since firms cannot reduce labor hours (the intensive margin), they rely more on adjusting employment (the extensive margin) ${ }^{11}$ Because firms cannot cut costs by reducing hours, the value of an employment match declines more than in the estimated economy so that firms reduce job vacancy postings more aggressively. As a consequence, the responses of unemployment overshoot those in the estimated economy.

\footnotetext{
${ }^{11}$ In the counterfactual economy, the decline of total hours is entirely driven by the decline of employment since labor hours per employed worker are fixed.
} 


\subsection{Further evidence for the labor channel}

The key implication of the labor channel is that real wages respond sluggishly to a housing demand shock that moves land prices. Because endogenous realwage rigidity is central to the labor channel and because we do not rely on the real-wage data for estimating the benchmark DSGE model, the most revealing test of our model is to assess its ability of predicting, out of sample, the wage rigidities implied by the data. The last row of Figure 2 shows that the estimated dynamic response of real wages to a housing demand shock is not only very small but also consistent with the BVAR result estimated with the data including real wages as one of the variables.

The empirical evidence and analysis provided in this section and Section 6.2 demonstrate that the labor channel, reinforced by the standard credit channel, plays an indispensable role in transmitting the fluctuations in the land price to large volatilities in the labor market. Our estimation shows that this transmission mechanism is quantitatively important.

\section{Discussions of model assumptions}

In this section we discuss the importance of several key model assumptions in relation to the strength of the labor channel as well as the fit to data.

\subsection{Households renting land}

One key assumption is that firms rent land from capitalists while households hold land to derive utility from it. In Supplemental Appendix G, we study an alternative model in which both firms and households rent land from capitalists who are the sole land owner ${ }^{12}$ Because a large share of the housing stock and land is owned by households in the actual economy, our benchmark model seems a more plausible approximation than does the alternative model. Nonetheless it would be informative to examine the impact of a negative housing demand shock in the alternative model, given the fact that a fraction of households in the actual economy rents housing services.

The negative housing demand shock shifts land use toward production, which would generate a boom in production. But there is a dominant offsetting effect. The resultant fall of the land price leads to a decline in the collateral value and hence a reduction in investment through the credit channel. This in turn reduces the match value. Moreover, a negative housing demand shock makes the household prefer consumption to housing services (the substitution effect) so that consumption increases. Unlike the benchmark model, there is no wealth effect in this alternative model (i.e,, the decline in the land price does not lead to a reduction in household consumption) because the household does not own

\footnotetext{
${ }^{12}$ In this case, the household's optimal land rental decision implies that the rental rate of housing is equal to the marginal rate of substitution between consumption and housing services for the household $\left(\mathrm{MRS}_{l t}\right)$; the land price is determined by the capitalist's land Euler equation.
} 
land. To support higher consumption, therefore, the household demands higher reservation wages, which leads to an increase in equilibrium real wages. Since real wages increase rather than decrease, unemployment rises far more than what the data imply. We re-estimate the alternative model with households renting land by fitting the same set of time-series data as in the benchmark model. The Shimer volatility ratio from the alternative model is 57.61 , with a $90 \%$ probability interval between 40.41 and 74.09 , much larger than a value of 25.34 in the data. Indeed we find that the alternative model's overall fit to the data is much worse.

To evaluate the quality of fit, we compute the $\log$ value of both posterior mode and marginal data density (MDD, also known as marginal likelihood, the most comprehensive measure of fit) for all models studied in the paper. The results are reported in Table 3 . Since the accuracy of the estimated MDD is extremely difficult to achieve, we estimate the MDD with millions of Markov Chain Monte Carlo (MCMC) simulations using three methods with different theoretical foundations. The estimates from these methods are very close, an indication of high accuracy. As one can see from the table, the MDD and the posterior mode for the alternative model with households renting land are smaller than those for the benchmark model by at least 295 in log value. Assuming the prior probability for each model is the same, these large differences for the two models suggest that the data overwhelmingly favor the benchmark model against the alternative.

The poor fit stems not just from the counterfactual increases in real wages following a negative housing demand shock, but also from two other critical dimensions in which the data are confronted. One is the land-price persistence in the data. Since the land price is determined only by the capitalist's land Euler equation, there is no competing demand from the household to exacerbate the fall of the land price (the lack of "the ripple effect" emphasized by Liu et al. (2013)). The resultant fall of the land price is thus short-lived. The other dimension is the observed comovement between consumption and investment. As the land price falls, the model's standard credit channel leads to a fall in business investment, while the substitution effect of the shock raises consumption. Thus, the alternative model produces opposite movements between consumption and investment in response to a housing demand shock, a damaging feature that is at odds with the data.

\subsection{Separable preferences}

Another key model assumption relates to nonseparable preferences over consumption and housing services for households, with a relative risk aversion parameter of $\gamma=2$ as a benchmark. To examine the importance of nonseparable preferences, we re-estimate the model that is identical to the benchmark except that the risk aversion parameter is fixed at $\gamma=1$.

We find that the fit of this alternative model to the data is much worse. As one can see from Table 3, the MDD for the separable-preference model with $\gamma=1$ is smaller than the MDD for the benchmark model by at least 85 in $\log$ value (the difference is 65 for the posterior mode). Again, the data 
overwhelmingly prefer our benchmark model to the alternative with separable preferences.

To gain intuition behind this finding, note the household's Euler equation for land holdings

$$
Q_{l t}=\mathrm{MRS}_{l t}+E_{t}\left[\mathrm{SDF}_{t+1} Q_{l, t+1}\right],
$$

where, assuming no habt formation for simplicity, the MRS and the stochastic discount factor (SDF) are given by

$$
\operatorname{MRS}_{l t}=\frac{\varphi_{L t} C_{h t}}{L_{h t}}, \quad \mathrm{SDF}_{t+1}=\beta_{h}\left(\frac{L_{h, t+1}^{\varphi_{L, t+1}}}{L_{h t}^{\varphi_{L t}}}\right)^{1-\gamma}\left(\frac{C_{h, t+1}}{C_{h t}}\right)^{-\gamma} .
$$

Since the unconstrained household is the marginal investor in the land market, land-price fluctuations are driven by two amplification components: the MRS for housing services and the SDF. Housing demand shocks $\left(\varphi_{L t}\right)$ directly affect the household's MRS. This amplification is independent of whether preferences are separable or not.

The SDF component, however, depends on nonseparable preferences for housing demand shocks to have direct impact on land prices, as shown in Equation (38). When preference are separable $(\gamma=1)$, the SDF is a function of consumption growth only and a housing demand shock thus has no direct impact on the SDF. Furthermore, the household has a lower degree of risk aversion, making consumption more responsive to technology shocks. In such a case, the model has to rely on large technology shocks to move consumption growth significantly so as to generate large volatility of the land price.

But technology shocks cannot generate realistic volatility of unemployment because of the well-known Shimer (2005) puzzle. Consequently, the fit of the model with $\gamma=1$ fares very poorly relative to the benchmark model. Such evidence lends support to nonseparability of preferences, which enhances the labor channel by allowing housing demand shocks to generate the observed comovements between land prices and unemployment.

\subsection{No housing demand shocks}

While a housing demand shock influences the labor-market dynamics through the labor channel, a natural question about the importance of this channel is whether models without such a shock can fit to the data. Since we fit the model to the six time-series variables in the data, we need replace the housing demand shock by another type of shock to make estimation feasible; otherwise the likelihood would become degenerate. We consider two types of shocks sequentially. One is a shock to job separation, in which case the job separation rate $(\rho)$ is time varying and follows a stationary $\operatorname{AR}(1)$ process; the other is a shock to labor disutility, in which case the labor-disutility parameter $\chi$ is time varying with a stationary AR(1) process. The separation shock shifts the Beveridge curve and the labor-disutility shock directly affects workers' reservation wages.

Table 3 reports the fit of each of these two alternative models. The log values of both posterior mode and MDD for these models are lower than those for the 
benchmark model by very large margins. The main explanation for such poor a fit is that, absent a housing demand shock, the model relies on large technology shocks to drive land-price fluctuations. As discussed in Section 6.2 however, the effects of a technology shocks are amplified through other channels than the labor channel. As a result, the model has difficulties in generating adequate volatility of unemployment relative to the volatility of labor productivity (the Shimer puzzle).

\section{Conclusion}

The dynamic relationship between the land price and the unemployment rate is a striking feature in the U.S. data. We construct and estimate a dynamic general equilibrium model to account for this relationship as well as those with other key macroeconomic variables. Our estimation shows that the labor channel, combined with the standard credit channel, provides a strong transmission mechanism that delivers not only the observed persistent comovements between land prices and unemployment, but also the observed high volatility ratio of labor market tightness to labor productivity as stressed by Shimer (2005).

To understand how the DMP labor market interacts with the housing market, we focus on obtaining a transparent economic mechanism that drives our empirical results and thus abstract from a host of other features which we could incorporate in future research. Miao et al. (2014), for example, provide a deeper interpretation of the housing demand shock and decompose it into three structural shocks for the purpose of explaining the wedge between house (land) and rental prices. Galí et al. (2012) take an explicit account of labor participation dynamics in their general equilibrium model. Christiano et al. (2013) offers an alternative framework for wage negotiations and focus their analysis on how the labor market responds to technology shocks as well as monetary policy shocks. It is our hope that the economic analysis provided by this paper offers essential ingredients for further research on the interactions between the housing market and the labor market and for improving policy designs.

\section{References}

Bernanke, B.S., Gertler, M., Gilchrist, S., 1999. The financial accelerator in a quantitative business cycle framework, in: Taylor, J.B., Woodford, M. (Eds.), The Handbook of Macroeconomics. first ed.. Elsevier. volume 1. chapter 21, pp. 1341-1393.

Blanchard, O.J., Galí, J., 2010. Labor markets and monetary policy: A new keynesian model with unemployment. American Economic Journal: Macroeconomics $2,1-30$.

Chaney, T., Sraer, D., Thesmar, D., 2012. The collateral channel: How real estate shocks affect corporate investment. American Economic Review 102, 2381-2409. 
Christiano, L., Motto, R., Rostagno, M., 2014. Risk shocks. American Economic Review 104, 27-65.

Christiano, L.J., Eichenbaum, M.S., Trabandt, M., 2013. Unemployment and business cycles. Working Paper, Northwestern University and Board of Governors of the Federal Reserve System.

Christiano, L.J., Trabandt, M., Walentin, K., 2011. Introducing financial frictions and unemployment into a small open economy model. Journal of Economic Dynamics \& Contral 35, 1999-2041.

Davis, M., Fisher, J., Veracierto, M., 2010. The role of housing in labor reallocation. Federal Reserve Bank of Chicago Working Paper 2010-18.

Davis, M.A., Heathcote, J., 2007. The price and quantity of residential land in the united states. Journal of Monetary Economics 54, 2595-2620.

Del Negro, M., Eggertsson, G., Ferrero, A., Kiyotaki, N., 2010. The great escape? a quantitative evaluation of the fed's non-standard policies. Manuscript, Princeton University.

den Haan, W.J., Ramey, G., Watson, J., 2000. Job destruction and propagation of shocks. American Economic Review 90, 482-498.

Diamond, P.A., 1982. Aggregate demand management in search equilibrium. Journal of Political Economy 90, 881-894.

Favilukis, J., Ludvigson, S.C., van Nieuwerburgh, S., 2010. The macroeconomic effects of housing wealth, housing finance, and limited risk-sharing in general equilibrium. NBER Working Paper No. 15988.

Galí, J., Smets, F., Wouters, R., 2012. Unemployment in an estimated new keynesian model. NBER Macroeconomics Annual 26, 329-360.

Gertler, M., Kiyotaki, N., 2010. Financial intermediation and credit policy in business cycle analysis, in: Friedman, B.M., Woodford, M. (Eds.), Handbook of Monetary Economics. Elsevier. volume 3. chapter 11, pp. 547-599.

Gertler, M., Sala, L., Trigari, A., 2008. An estimated monetary dsge model with unemployment and staggered nominal wage bargaining. Journal of Money, Credit and Banking 40, 1713-1764.

Gertler, M., Trigari, A., 2009. Unemployment fluctuations with staggered nash wage bargaining. Journal of Political Economy 117.

Hagedorn, M., Manovskii, I., 2008. The cyclical behavior of equilibrium unemployment and vacancies revisited. American Economic Review 98, 1692-1706.

Hall, R.E., 2005. Employment fluctuations with equilibrium wage stickiness. American Economic Review 95, 50-65. 
Hall, R.E., 2011a. The high sensitivity of economic activity to financial frictions. Economic Journal 121, 351-378.

Hall, R.E., 2011b. The long slump. American Economic Review 101, 431-469.

Hall, R.E., Milgrom, P.R., 2008. The limited influence of unemployment on the wage bargain. American Economic Review 98, 1653-1674.

Hornstein, A., Krusell, P., Violante, G.L., 2005. Unemployment and vacancy fluctuations in the matching model: Inspecting the mechanism. Federal Reserve Bank of Richmond Economic Quarterly 91, 19-51.

Iacoviello, M., 2005. House prices, borrowing constraints, and monetary policy in the business cycle. American Economic Review 95, 739-764.

Iacoviello, M., Neri, S., 2010. Housing market spillovers: Evidence from an estimated dsge model. American Economic Journal: Macroeconomics 2.

Jermann, U., Quadrini, V., 2012. Macroeconomic effects of financial shocks. American Economic Review 102, 238-271.

Justiniano, A., Michelacci, C., 2011. The cyclical behavior of equilibrium unemployment and vacancies in the us and europe, in: Frankel, J., Pissarides, C.A. (Eds.), NBER International Seminar on Macroeconomics 2011. University of Chicago Press. chapter 4, pp. 169-235.

Keane, M., Rogerson, R., 2012. Micro and macro labor supply elasticities: A reassessment of conventional wisdom. Journal of Economic Literature 50, 464-76. URL: http://www .aeaweb.org/articles.php?doi=10.1257/jel. 50.2.464, doi:10.1257/jel.50.2.464

Kiyotaki, N., Moore, J., 1997. Credit cycles. Journal of Political Economy 105, 211-248.

Kocherlakota, N.R., 1996. The equity premium: It's still a puzzle. Journal of Economic Literature 34, 42-71.

Liu, Z., Waggoner, D.F., Zha, T., 2011. Sources of macroeconomic fluctuations: A regime-switching dsge approach. Quantitative Economics 2, 251-301.

Liu, Z., Wang, P., 2014. Credit constraints and self-fulfilling business cycles. American Economic Journal: Macroeconomics 6, 32-69.

Liu, Z., Wang, P., Zha, T., 2009. A theory of housing demand shocks. Unpublished Manuscript.

Liu, Z., Wang, P., Zha, T., 2013. Land-price dynamics and macroeconomic fluctuations. Econometrica 81, 1147-1184.

Lubik, T.A., 2009. Estimating a search and matching model of the aggregate labor market. Economic Quarterly 95, 101-120. 
Lucas Jr., R.E., 2003. Macroeconomic priorities. American Economic Review 93, 1-14.

Meng, X.L., Wong, W.H., 1996. Simulating ratios of normalising constants via a simple identity: a theoretical exploration. Statistica Sinica 6, 831-860.

Mian, A., Sufi, A., 2014. What explains the 2007-2009 drop in employment. Econometrica 82, 2197-2223.

Mian, A., Sufi, A., Rao, K., 2013. Household balance sheets, consumption, and the economic slump. Quarterly Journal of Economics 128, 1687-1726.

Miao, J., Wang, P., Xu, L., 2015. Stock market bubbles and unemployment. Economic Theory 61, 273-307.

Miao, J., Wang, P., Zha, T., 2014. Liquidity premia, price-rent dynamics, and business cycles. NBER Working Paper No. 20377.

Monacelli, T., Quadrini, V., Trigari, A., 2011. Financial markets and unemployment. Unpublished Manuscript, University of Bocconi.

Mortensen, D.T., 1982. Property rights and efficiency in mating, racing, and related games. American Economic Review 72, 968-979.

Nichols, J.B., Oliner, S.D., Mulhall, M.R., 2013. Swings in commercial and residential land prices in the united states. Journal of Urban Economics 73, $57-76$.

Petrongolo, B., Pissarides, C.A., 2001. Looking into the black box: A survey of the matching function. Journal of Economic Literature 39.

Petrosky-Nadeau, N., 2014. Credit, vacancies and unemployment fluctuations. Review of Economic Dynamics 17, 191-205.

Petrosky-Nadeau, N., Wasmer, E., 2013. The cyclical volatility of labor markets under frictional financial markets. American Economic Journal: Macroeconomics 5, 193-221.

Piazzesi, M., Schneider, M., Tuzel, S., 2007. Housing, consumption, and asset pricing. Journal of Financial Economics 83, 531-569.

Pissarides, C.A., 1985. Short-run equilibrium dynamics of unemployment vacancies, and real wages. American Economic Review 75, 676-690.

Ravenna, F., Walsh, C.E., 2008. Vacancies, unemployment, and the phillips curve. European Economic Review 52, 1494-1521.

Shimer, R., 2005. The cyclical behavior of equilibrium unemployment and vacancies. American Economic Review 95, 25-49. 
829 Sims, C.A., Waggoner, D.F., Zha, T., 2008. Methods for inference in large 830 multiple-equation markov-switching models. Journal of Econometrics 146, 831 $\quad 255-274$.

${ }_{832}$ Sims, C.A., Zha, T., 1998. Bayesian methods for dynamic multivariate models. 833 International Economic Review 39, 949-968.

${ }_{834}$ Sims, C.A., Zha, T., 1999. Error bands for impulse responses. Econometrica $835 \quad 67,1113-1155$.

836 Zha, T., 1999. Block recursion and structural vector autoregressions. Journal ${ }_{837}$ of Econometrics 90, 291-316. 
Table 1: Targeted steady state variables and calibrated parameter values

\begin{tabular}{|c|c|c|c|}
\hline $\begin{array}{l}\text { Parameter or steady } \\
\text { state variable }\end{array}$ & Description & Value & Source \\
\hline$a$ & Job match elasticity & 0.5 & $\begin{array}{l}\text { Petrongolo and Pissarides } \\
\text { Hall and Milgrom }(2001) \\
\text { Gertler and Trigari }(2009) \\
\end{array}$ \\
\hline$b / W$ & Replacement ratio & 0.75 & Christiano et al. $(2013)$ \\
\hline$\frac{\vartheta}{1+\vartheta}$ & Workers' bargaining weight & 0.3 & Christiano et al. $(2011)$ \\
\hline$\alpha$ & Capital income share & 0.33 & U.S. Data \\
\hline$I / Y$ & Investment-output ratio & 0.275 & U.S. Data \\
\hline$K / Y$ & Capital-output (quarterly) & 5.0 & U.S. Data \\
\hline$C_{c} / C$ & Capitalists' consumption share & 0.06 & U.S. Data \\
\hline$\rho$ & Job separation rate & 0.12 & Blanchard and Galí (2010) \\
\hline$\xi$ & Leverage ratio & 0.75 & Liu et al. (2013) \\
\hline$\frac{\kappa v}{Y}$ & $\begin{array}{l}\text { Cost of posting and filling } \\
\text { a job vacancy }\end{array}$ & 0.005 & $\begin{array}{l}\text { Hagedorn and Manovskii 2008) } \\
\text { Christiano et al. (2013) }\end{array}$ \\
\hline$q^{u}$ & Job finding rate (quarterly) & 0.67 & $\begin{array}{l}\text { Blanchard and Galí (2010) } \\
\text { Christiano et al. }(2013) \\
\end{array}$ \\
\hline$q^{v}$ & Job filling rate (quarterly) & 0.7 & $\begin{array}{ll}\text { den Haan et al. } & 2000) \\
\text { Christiano et al. } & (2013) \\
\end{array}$ \\
\hline$\gamma$ & Risk aversion & 2 & $\begin{array}{l}\text { Kocherlakota }(1996) \\
\text { Lucas Jr. }(2003)\end{array}$ \\
\hline
\end{tabular}

Note: "Source" indicates where the value is based on. 
Table 2: Prior and posterior distributions of key model parameters

\begin{tabular}{llllllll}
\hline \hline & \multicolumn{3}{c}{ Prior } & & \multicolumn{3}{c}{ Posterior } \\
\cline { 2 - 3 } Parameter & Distribution & low & high & & Mode & Low & High \\
\hline$\eta_{c}$ & Beta & 0.025 & 0.776 & & 0.996 & 0.988 & 0.997 \\
$\eta_{h}$ & Beta & 0.025 & 0.776 & & 0.166 & 0.048 & 0.329 \\
$\Omega$ & Gamma & 0.171 & 10.00 & & 0.114 & 0.084 & 0.170 \\
$\gamma_{2}$ & Gamma & 0.171 & 10.00 & & 0.729 & 0.410 & 1.611 \\
$\nu$ & Gamma & 0.086 & 5.000 & & 0.001 & 0.000 & 0.006 \\
$\omega_{2}$ & Gamma & 0.048 & 2.821 & & 0.099 & 0.089 & 0.127 \\
$100\left(\lambda_{z}-1\right)$ & Gamma & 0.100 & 1.500 & & 0.478 & 0.435 & 0.538 \\
\hline$\rho_{L}$ & Beta & 0.025 & 0.776 & & 0.998 & 0.995 & 0.999 \\
$\rho_{\vartheta}$ & Beta & 0.025 & 0.776 & & 0.966 & 0.947 & 0.986 \\
$\rho_{m}$ & Beta & 0.025 & 0.776 & & 0.983 & 0.962 & 0.992 \\
$\rho_{z p}$ & Beta & 0.025 & 0.776 & & 0.217 & 0.107 & 0.330 \\
$\rho_{z m}$ & Beta & 0.025 & 0.776 & & 0.952 & 0.929 & 0.960 \\
$\rho_{\xi}$ & Beta & 0.025 & 0.776 & & 0.966 & 0.957 & 0.985 \\
\hline$\sigma_{L}$ & Inv-Gamma & $1.00 \mathrm{e}-04$ & 2.000 & & 0.077 & 0.070 & 0.122 \\
$\sigma_{\vartheta}$ & Inv-Gamma & $1.00 \mathrm{e}-04$ & 2.000 & & 0.039 & 0.037 & 0.045 \\
$\sigma_{m}$ & Inv-Gamma & $1.00 \mathrm{e}-04$ & 2.000 & & 0.019 & 0.018 & 0.021 \\
$\sigma_{z p}$ & Inv-Gamma & $1.00 \mathrm{e}-04$ & 2.000 & & 0.008 & 0.007 & 0.010 \\
$\sigma_{z m}$ & Inv-Gamma & $1.00 \mathrm{e}-04$ & 2.000 & & 0.014 & 0.013 & 0.016 \\
$\sigma_{\xi}$ & Inv-Gamma & $1.00 \mathrm{e}-04$ & 2.000 & & 0.038 & 0.032 & 0.049 \\
\hline
\end{tabular}

Note: "Low" and "high" denotes the bounds of the $90 \%$ probability interval for each parameter. 
Table 3: Measures of model fit for various models: log value

\begin{tabular}{|c|c|c|c|c|c|}
\hline & \multirow{2}{*}{$\begin{array}{c}\text { Benchmark model } \\
\text { Nonseparability } \\
(\gamma=2)\end{array}$} & \multicolumn{2}{|c|}{ Alternative specifications } & \multicolumn{2}{|c|}{ Alternative shocks } \\
\hline & & $\begin{array}{l}\text { Households } \\
\text { renting land }\end{array}$ & $\begin{array}{l}\text { Separability } \\
\quad(\gamma=1)\end{array}$ & $\begin{array}{c}\text { Job separation } \\
\text { shock }\end{array}$ & $\begin{array}{l}\text { disutility } \\
\text { shock }\end{array}$ \\
\hline Mode & 2422.15 & 2125.12 & 2356.11 & 1264.32 & 2340.66 \\
\hline MDD (SWZ) & 2337.84 & 2041.61 & 2250.06 & 1254.40 & 2236.21 \\
\hline MDD (Mueller) & 2337.82 & 2041.60 & 2250.05 & 1254.53 & 2234.98 \\
\hline MDD (Bridge) & 2337.81 & 2041.61 & 2250.06 & 1254.13 & 2234.46 \\
\hline
\end{tabular}

Note: "Mode" stands for the value of posterior mode; "MDD" stands for the marginal data density (the same concept as the marginal likelihood). "SWZ" represents the method of Sims et al. (2008). The Mueller method (Mueller) is described in Liu et al. (2011). The bridge-sampling method (Bridge) is developed by Meng and Wong (1996). Separability and nonseparability refer to the household's preference. For each MDD estimate, we simulate two millions of posterior draws and one million of proposal draws. On an 8-core modern desktop, finding each posterior mode takes about 30 hours; estimation of each MDD takes about 40 hours. 


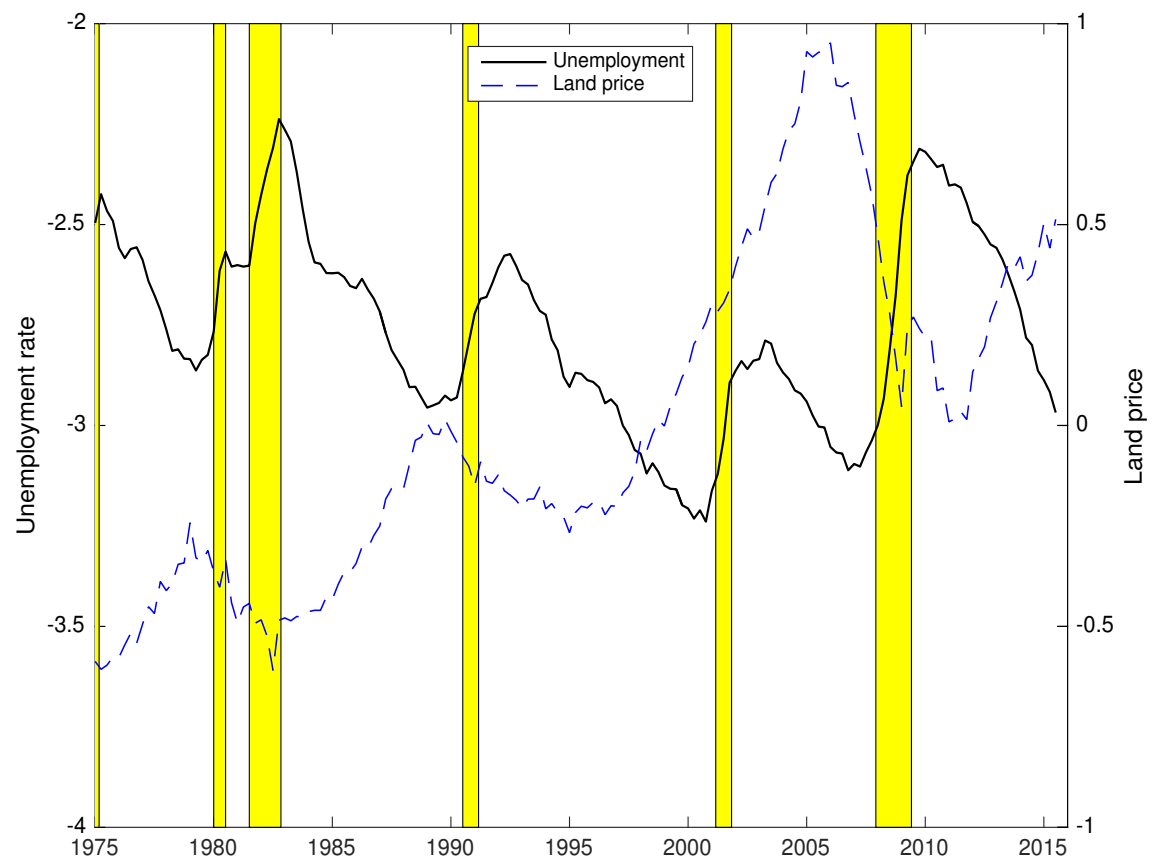

Figure 1: Log unemployment rate (left scale) and log real land price (right scale). The shaded bars mark the NBER recession dates. 

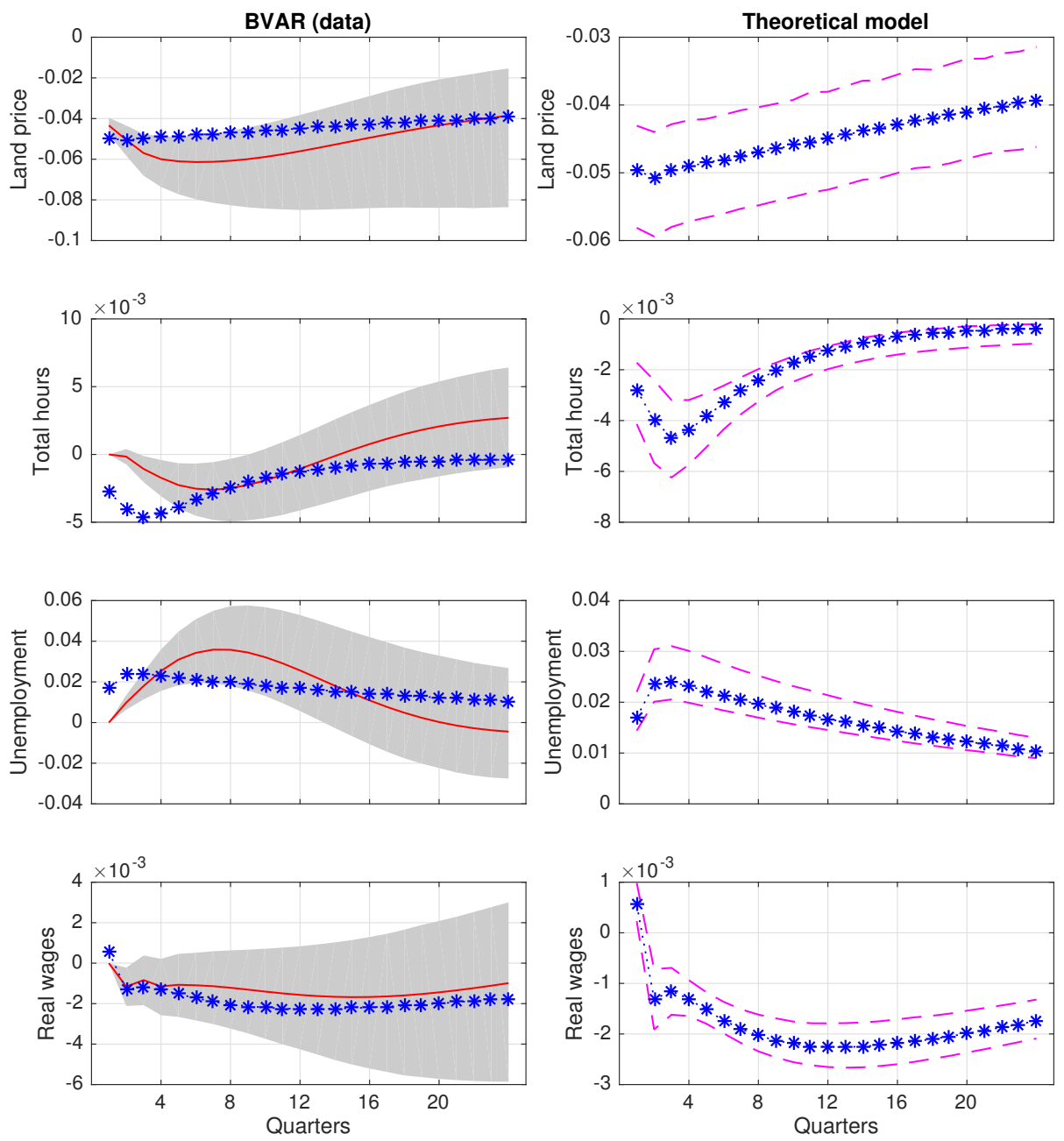

Figure 2: Left column: impulse responses to a negative one-standard-deviation land-price shock in a recursive BVAR with the land price ordered last. Right column: impulse responses to a negative one-standard-deviation housing demand shock in the DSGE model. All variables are in log level. Solid lines in the left column represent the estimated dynamic responses from the BVAR and the shaded area represents the corresponding $90 \%$ probability bands. Dashed lines in the right column represent the $90 \%$ probability bands of impulse responses for the DSGE model. Asterisk lines in both columns represent the estimated dynamic responses for the DSGE model. 

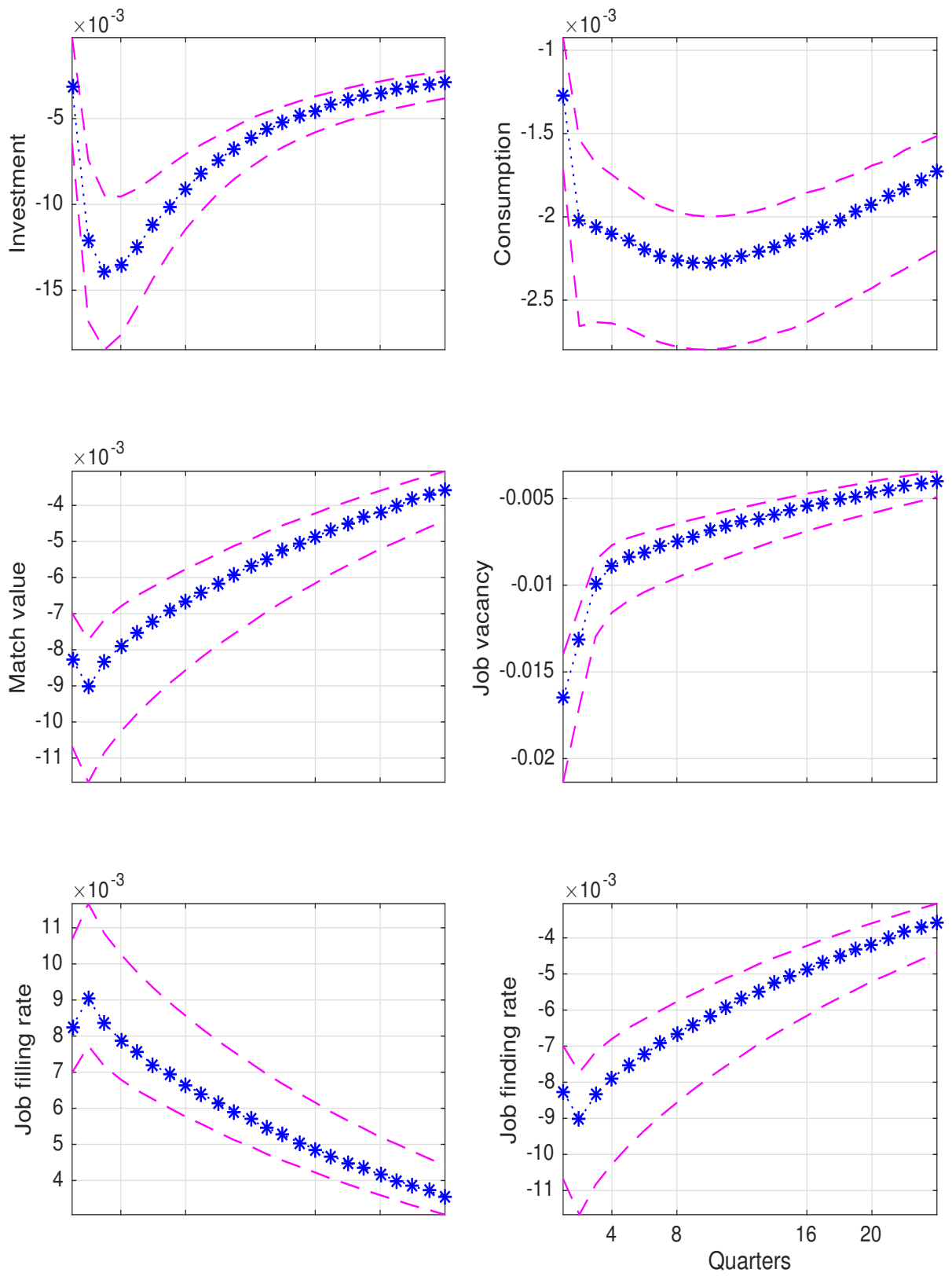

Figure 3: Impulse responses of investment, consumption, and labor-market variables to a negative one-standard-deviation shock to housing demand. Asterisk lines represent the estimated responses and dashed lines demarcate the $90 \%$ probability bands. 

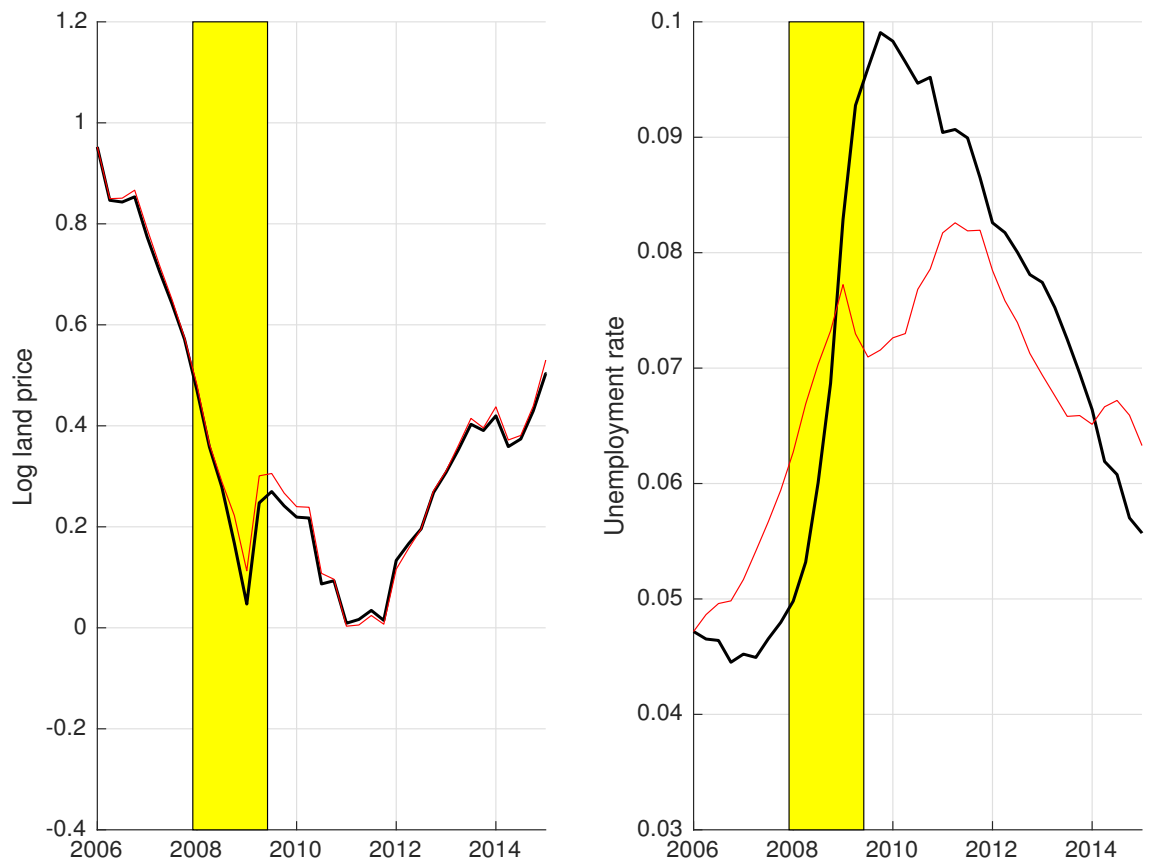

Figure 4: The Great Recession episode: counterfactual paths of the log land price and the unemployment rate, conditional on the estimated housing demand shocks only. Each graph shows the actual path (thick line), counterfactual path from the benchmark model (thin line), and the Great Recession period (shaded area). 


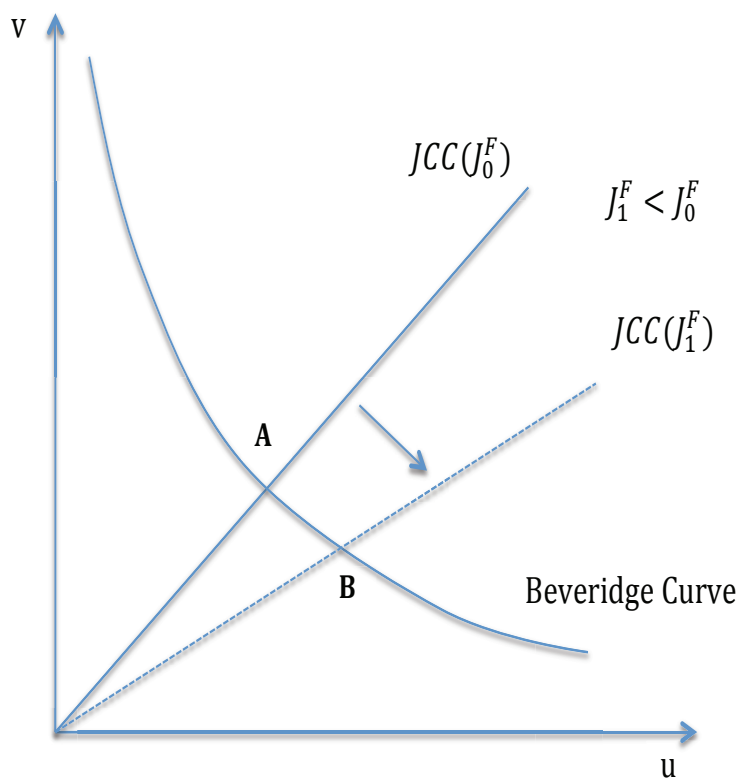

Figure 5: Search-matching frictions in the labor market: an illustration. JCC stands for the job creation curve and $J^{F}$ is the value of a new employment match. 

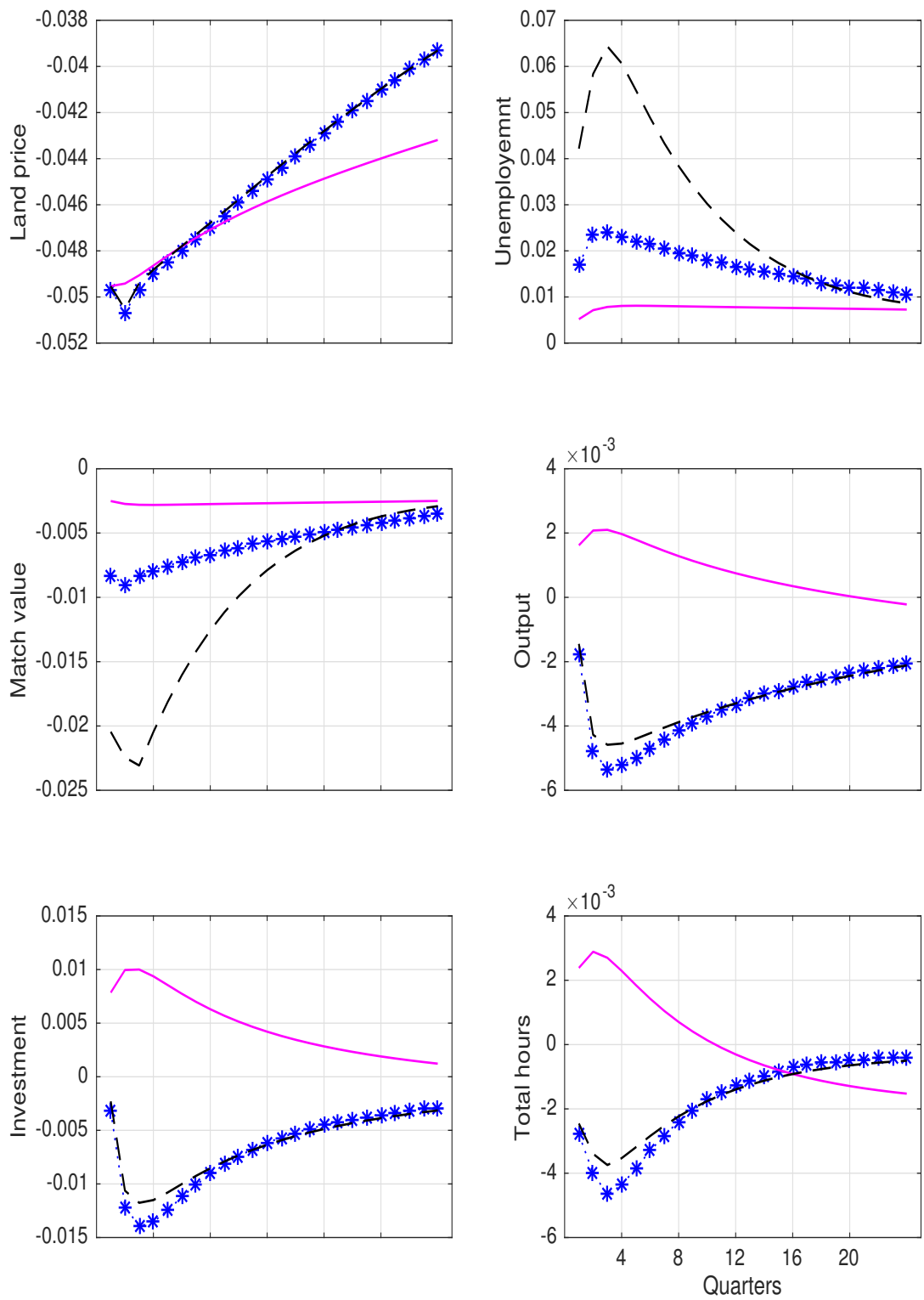

Figure 6: Impulse responses to a negative one-standard-deviation shock to the housing demand in the estimated model and in the two counterfactual models. Asterisk lines represent the estimated responses, solid lines represent the responses in the counterfactual economy in which credit does not respond to changes in asset values, and dashed lines represent the responses in the counterfactual economy in which each worker's hours do not adjust. Total hours are equal to $h_{t} N_{t}$. 

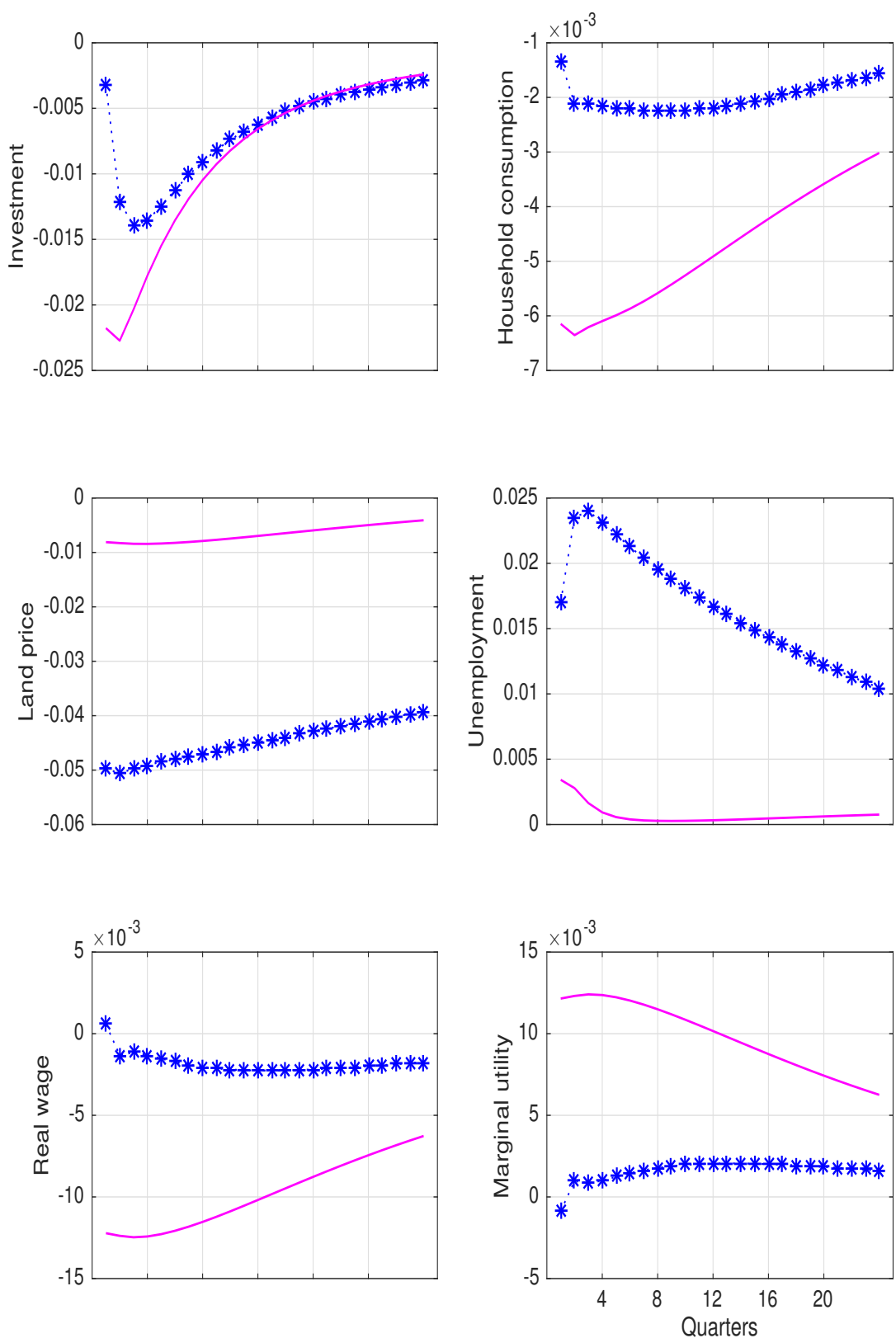

Figure 7: Impulse responses to a negative one-standard-deviation housing demand shock (asterisk lines) vs those to a negative stationary technology shock (solid lines). The label "Marginal utility" is the marginal utility of households' consumption. 